successfully employed in the study of d.c. discharges, but, so far as we are aware, it has not yet been used in a.c. discharges. In the latter case, a number of difficulties have to be overcome before it can be successfully applied.

In dealing with d.c. discharge, the space-potential is generally referred to that of one of the electrodes maintaining the discharge; it cannot be so referred in the case of an a.c. discharge. Moreover, in high frequency discharges obtained with external sleeve electrodes-a subject of many recent investigationsthe volt-ampere characteristic of the Langmuir ' exploring electrode' cannot be obtained when one of the external electrodes is used in the circuit.

We have been able to overcome this difficulty by using an extra bobbin-shaped internal electrode to

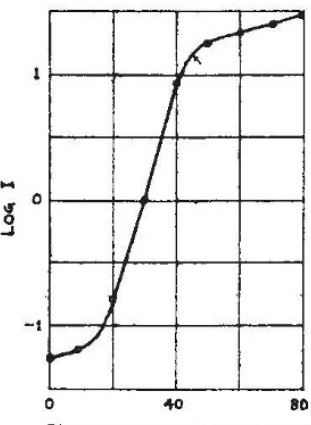

POTENTUL OF COLLCTOR W VOLTS

FiG. 1. - Characteristic $\log I$, $\checkmark$ curve. complete the circuit through the 'exploring electrode'. This internal electrode is kept outside the region of the main discharge so as not to affect it in any way. A typical volt-ampere characteristic as obtained by us in oxygen at a pressure of $0.14 \mathrm{~mm}$. of mercury is plotted in Fig. 1 with the logarithm of the current to the 'exploring electrode' as ordinate and its voltage as abscissa. It is to be observed that the nature of the curve is similar to that obtained in d.c. discharges as described and fully discussed in "Conduction of Electricity through Gases" (Methuen's Monograph Series) by K. G. Emeléus.

From such characteristic curves we have measured not only the variation of the space-potential but also the concentration and the average velocity of the electrons in different parts of the discharge. A typical set of results is given below :

Oxygen under pressure $0.14 \mathrm{~mm}$. of $\mathrm{Hg}$. Distance between electrodes, $15 \mathrm{~cm}$. Frequency, $1.2 \times 10^{6}$.

\begin{tabular}{|c|c|c|c|}
\hline $\begin{array}{c}\text { Distance from } \\
\text { left electrode. }\end{array}$ & $\begin{array}{c}\text { Space } \\
\text { potential. }\end{array}$ & $\begin{array}{c}\text { Average electron } \\
\text { velocity (volts } \\
\text { per cm.). }\end{array}$ & $\begin{array}{c}\text { Concentration of } \\
\text { electrons. }\end{array}$ \\
\hline $4.5 \mathrm{~cm}$. & 24 volts & 7.83 & $2 \cdot 62 \times 10^{8}$ per c.c. \\
\hline
\end{tabular}

A detailed description of the method with discussion of the results is being published elsewhere.

Incidentally, it may be mentioned that C. J. Brasefield (Phys. Rev. $35 ; 1930$ ) has carried out measure. ments of electron velocities in high frequency discharge by a spectroscopic mothod, remarking that it is extremely difficult, if not impossible, to employ Langmuir's ' exploring electrode ' method for measurements in high frequency discharge. The above application of Langmuir's method, the success of which is evidenced by the agreement of some of Brasefield's results with ours, was developed by us before Brasefield's paper came to our notice and shows that his remark regarding the difficulties apprehended, but not specifically mentioned in the paper, is not warranted.

Wireless Laboratory,

D. BanerJi.

R. Ganguli.

University College of Science, Calcutta, July 4.

No. 3174, VoL. 126]

\section{The Possibility of Separating Two Forms of the} Ammonia Molecule.

A FEw years ago it was observed by Baly and Duncan (Jour. Chem. Soc., 121, $1008 ; 1922$ ) that ammonia gas drawn quickly from a cylinder containing liquid ammonia was less rapidly decomposed on a hot platinum wire than gas drawn slowly from the same cylinder, or obtained in certain other ways. They offered as a possible explanation that ammonia molecules may exist in two forms of different reactivity, which may be separated or perhaps converted entirely into one form under suitable conditions.

Since that time, spectroscopic evidence has indicated the existence of two, or perhaps several, kinds of ammonia gas molecule, which presumably differ in certain symmetry properties, and it has been suggested by Tronstadt (Z.f. Phys. Ch., Abt. B, 5, 355; 1929) that a separation of such forms may have been achieved by Baly and Duncan.

Although this explanation of the different decomposition rates observed by these experimenters seemed to me rather improbable, it would be a very important fact if such a separation can occur under the conditions of ordinary chemical experiments, especially if the forms separated should have appreciably different reactivities. Consequently the question has been put to a spectroscopic test by a study of three of the absorption bands of ammonia gas in the red and near infra-red, making comparisons on gas obtained under varying conditions. The bands chosen were those at $8800 \mathrm{~A}$., $7920 \mathrm{~A}$., and $6474 \mathrm{~A}$., which have been analysed by Badger and Mecke (Z. f. Phys. Ch., Abt. B, 5, 333; 1929) and Badger (Phys. Rev., 35, 1038; 1930). Though they are perhaps not yet understood in all their finer details, it seems quite certain that all these bands give evidence for two forms of ammonia molecule.

In the case of the bands at $8800 \mathrm{~A}$. and $6474 \mathrm{~A}$., ammonia gas drawn rapidly from a cylinder (a 10 -litre vessel was filled in 3 sec.) was compared with gas drawn slowly from the same cylinder, and with gas which had stood five days in the absorption vessel. In the case of the band at $7920 \mathrm{~A}$. a similar comparison was made, and in addition a sample of liquid ammonia was fractionated and the gas obtained from the first and last fourths was compared. The gas evaporated from solid ammonia which had been kept at liquid air temperature twenty-four hours was also studied.

In every case the same absorption spectrum was obtained. Neither the intensity of the bands as a whole nor the relative intensities of the various band lines was appreciably different from the usual in the case of any of the gas samples.

Consequently it is very unlikely that the results of Baly and Duncan are to be explained by a separation of two forms of ammonia molecule, or that such a separation occurs under ordinary experimental conditions. RICHARD M. BADGER.

California Institute of Technology, Pasadena, California, July 9 .

\section{Isomorphism and Chemical Homology.}

THE ions of the formula $\mathrm{AX}_{4}$ (for example, $\mathrm{SiO}_{4}$, $\mathrm{CrO}_{4}$, etc.) have been studied, and their fundamental vibration frequencies can be accounted for by simple molecular models : the polarisability of the oxygen ion in all these cases where it enters is of the same order as that given by the refraction of the crystalline oxides. It is admitted that in these cases the linkages are ionic. 